\title{
AQUALUNG DIVING FOR THE PARALYSED
}

\author{
By Dr. Hans Frankel, M.B., B.S., M.R.C.P. \\ National Spinal Injuries Centre, Stoke Mandeville, Aylesbury
}

Abstract. Aqualung diving is practised by some paralysed sportsmen. Close cooperation between suitable disabled persons and their medical advisers is emphasised.

Swimming has long been recognised as an ideal sport for the paralysed, both as a competitive sport and more importantly, as a recreational sport. When carried out under reasonable conditions, swimming is a perfectly safe sport for the paralysed. In contrast, underwater swimming, even for the able-bodied is a hazardous procedure and comes within the definition of 'high risk' or adventure sports.

On theoretical grounds alone, I was much opposed to paralysed sportsmen engaging in what I considered to be an unnecessarily hazardous pursuit for them. However, a group of paralysed sportsmen who had experience of aqualung diving prior to their paralysis, have convinced me otherwise; this group was led by Dr. Nicholas Flemming and I am indebted to him for the information contained in this talk.

Medical Aspects of Aqualung Diving for the Non-disabled. The medical problems are caused essentially by $(a)$ the necessity of providing air for breathing while underwater and $(b)$ the effects of the increased pressures found underwater. Figure I shows the effects of different depths of water on the volume of air and on its pressure. A submersion to $10 \mathrm{~m}$. under sea water halves the volume of air and doubles the pressure.

Skin Diving. It is possible to remain underwater for approximately one minute without any special apparatus whatsoever, and with special training this time can be slightly prolonged. Very skilled 'skin divers' have been known to dive to depths of up to $25 \mathrm{~m}$.

Snorkelling. With the aid of some 'snorkel' device or a thin reed, it is possible to breathe air from the surface while submerged. However, due to the increased pressure while underwater, it is only possible from a few centimetres below the surface. Snorkelling is an interesting method of observing the sea bed from just below the surface and its only medical danger apart from simple drowning and an inadvertent inhalation of water, is sun burn of the back.

Diving with Portable Breathing Equipment (Scuba Diving, Aqualung Diving). Modern equipment has automatic demand valves. The cylinders contain either compressed air or a mixture of oxygen and an inert gas other than

${ }^{1}$ Paper read at the Postgraduate Seminar on Medical Aspects of Sport for the Disabled held on 9 and Io May 1975 at the Stoke Mandeville Sports Stadium for the Paralysed and other Disabled and at the Sir Henry Floyd Auditorium, Stoke Mandeville Hospital. 


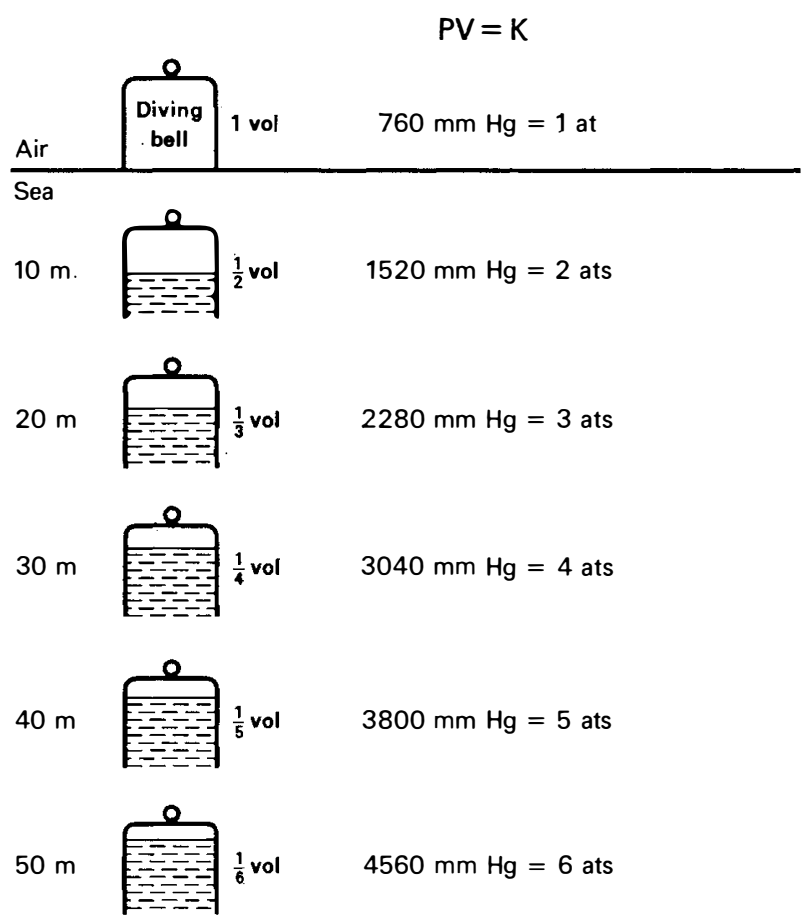

FIG. I

By kind permission of Dr Stanley Miles.

nitrogen, such as helium. With such apparatus it is possible for trained divers to go to depths of up to $40 \mathrm{~m}$. for varying lengths of time, if adequate precautions against complications are taken.

Diving Suits. With the aid of diving suits connected by line to an air supply on the surface, it is possible to dive to depths of up to I50 m. However, in these suits divers are exposed to the full pressure of the water and adequate precautions. against complications must be taken.

Diving Bells. Open bottom diving bells are one of the oldest methods of working at depth. Again the divers are exposed to the full pressure of the depth at which they are working (see fig. I).

Submarines and Deep Water Pressure Chambers. These are extremely strong, rigid structures where pressure can be maintained at surface atmospheric pressure. Apart from the problems of maintaining an adequate supply of new air, there are no great medical problems unless the occupants have to escape from the vessel while it is submerged to a depth. 


\section{MEDICAL COMPLICATIONS OF FREE DIVING WITH PORTABLE BREATHING EQUIPMENT}

\section{Drowning.}

2. Pulmonary Baro-Trauma. This may occur if there is a too rapid ascent from deep water and may occur irrespective of the duration of the preceding dive. It is due to rapid expansion of the volume of gas within the thorax as the diver passes from a high to a lower pressure depth. It can be prevented by progressive exhalation during the ascent (same technique as used when escaping from submarine). The main manifestation of pulmonary trauma are (a) burst lung $(b)$ air embolism.

3. Decompression Sickness. If the diver remains submerged to a significant depth for more than a few minutes, increasing amounts of the inert gas in his breathing mixture (nitrogen or helium) becomes dissolved in the blood. Except at very great depths, it is of no medical significance, as long as the diver remains submerged. However, if the diver ascends too rapidly, the inert gas will come out of solution in a gaseous form, not only in the lungs but also within the blood vessels. The gas bubbles so formed may prevent the passage of blood through medium sized or small blood vessels and may cause temporary or permanent damage to the tissues supplied by those vessels. The most common manifestations of decompression sickness are $(a)$ bends, including paralysis, dementia and blindness $(b)$ rashes $(c)$ bone necrosis.

Decompression sickness can usually be avoided by gradual decompression following prolonged dives and for this purpose there are various standard tables to advise the diver on the length of time he has to wait at any level. However, there is no universal agreement on these figures and in any case, the majority of pressure gauges used by divers are relatively inaccurate and for this reason bends still occur too frequently. If the symptoms of bends should develop, it is possible to control the condition by returning to a higher pressure zone i.e. either by returning to a greater depth or by entering a decompression chamber. The first of these is obviously difficult for a diver with a limited amount of air in his cylinder. The bends remain a major problem for aqualung divers, many of whom have experienced it to a greater or lesser degree.

The brain and spinal cord are particularly sensitive to interruptions in the blood supply and if divers with spinal cord involvement are not rapidly and effectively recompressed, there is likely to be permanent damage and we have, in fact, had four patients with permanent, partial paralysis from this cause in the National Spinal Injuries Centre, Stoke Mandeville Hospital.

4. Narcosis. Exposure to high pressure gases may cause narcosis preceded by irrational or a 'drunken' behaviour.

5. Hypothermia.

6. Effect on Ears and Eyes. If there is any loss of patency of the eustachian tube, severe damage to the ear may occur on submerging and ascending. Subjects with any ear disease or anyone with an upper respiratory infection, should not dive.

Vision under water may be defective because of low light intensity and because the power of focusing of the eye is reduced when the eye is in contact with the water. This latter problem can be overcome by wearing a water-tight face mask. 


\section{AQUALUNG DIVING FOR THE PARALYSED}

As mentioned previously, aqualung diving is an adventure sport and as such can never be totally devoid of risk. It is a sport that appeals to particularly independent and determined people who will not be put off by the additional risks which their paralysis brings with it. However, to keep the risks to tolerable levels, certain guide lines should be observed.

I. Selection of Patients. As there is a probability of being subjected to minor or moderate degrees of temporary tissue hypoxia, patients whose paralysis is caused by vascular lesions of the nervous system or who have incomplete spinal cord lesions, should not dive, as their neurological state may be temporarily or permanently worsened (arteriovenous malformation of the cord, angimoas, anterior spinal artery thrombosis, strokes, post-head injury syndromes and patients with incomplete spinal cord lesions from any cause). Patients who are suitable are patients who have traumatic paraplegia with complete lesions, poliomyelitis and peripheral nerve lesions. Until there is some further experience, I would also exclude all those whose lesions are above $\mathrm{T}_{5}$ segment because of their relatively inefficient respiratory resources and their extensive paralysis. Apart from their paralysis, patients should have the same standard of health which are required by the non-disabled (in this country by the official body of the British Sub-Aqua Club (B.S.A.C.)).

Paralysed divers are obviously subjected to greater risks and need adequate training and supervision. However, Dr. Nicholas Flemming has described in detail how paraplegics with lesions below $\mathrm{T}_{5}$ may become competent to dive with aqualung apparatus to depths of $7 \mathrm{~m}$. It is possible that greater depths can be obtained with further training.

Dr. Nicholas Flemming has evolved the following basic rules for sea diving by disabled people:

(a) Obey all usual diving regulations and medical regulations concerning diving.

(b) Your safety factor is always lower than for an able-bodied diver.

(c) The dive begins when you leave home and ends when you get back home safely.

(d) NEVER DIVE ALONE.

(e) ALWAYS DIVE WITH TWO ABLE-BODIED EXPERIENCED DIVERS CLOSE TO YOU IN THE WATER; THAT IS WITHIN $5 \mathrm{~m}$. OR VISIBILITY RANGE WHICHEVER IS THE SMALLER. THERE MUST BE AT LEAST ONE DIVER IN THE COVER BOAT AND A BOATMAN.

(f) Always plan and survey your entry into and exit from the water with the people who will be helping you.

(g) Make sure that your diving companions know your limitations in terms of diving safety and general medical care.

(h) You cannot use your hands to adjust your equipment or carry out work while you are swimming. Avoid situations which require both at once.

(i) Never dive in a current stronger than you can swim against for a long time.

(j) Avoid abrasions and cuts from reefs and rocks. Do not touch corals.

(k) Do not make dives requiring decompression stops. 
(l) Never go under overhangs.

(m) Never go inside caves or wrecks.

(n) Never dive at night.

(o) Never dive in visibility less than $3 \mathrm{~m}$. It is impossible for your companions to stay sufficiently close to you to give rapid help in these conditions.

$(p)$ Never dive in waves of more than $2 \mathrm{~m}$. or a strong wind.

(q) Plan all diving operations with multiple redundant safety measures and fail-safe procedures.

( $r$ ) Paralysed divers tend to get cold more quickly than able-bodied divers and should take additional precautions against hypothermia. They also need particular care to avoid burns if they have to re-warm themselves.

\section{CONCLUSION}

In spite of the difficulties involved, it has now been demonstrated that it is possible for paralysed sportsmen to dive to moderate depths with aqualung apparatus. As in other sports, the paralysed will require help and cooperation of trainers and coaches specialising in that sport. In this country these facilities will be provided by the B.S.A.C. I have a list of similar organisations in most countries which I can provide on request.

I would stress again, that if this exciting sport is to be made available to suitably disabled sportsmen, it will require close cooperation between those medical practitioners who understand their patients' disability and experts in aqualung diving. 